\title{
The Fertility of Female Immigrants to Europe from Christian and Muslim Countries
}

\author{
Morten Blekesaune \\ Professor, Department of Sociology and Social Work, University of Agder, \\ Kristiansand, Norge, Norway \\ morten.blekesaune@uia.no
}

\begin{abstract}
This article investigates the fertility of female immigrants to Europe in relation to the characteristics of individual women $(n=1,667)$, their countries of origin in Africa, Asia and Latin-America $(n=68)$ and the European country where they reside $(n=22)$, using the European Social Survey (ESs) collected between 2010 and 2017 (rounds 5 to 8). Many immigrants have fertility outcomes that converge towards the native fertility of their country of residence in Europe, a surprisingly strong factor. Immigrants from Muslim countries have higher fertility, though, and they compress their fertility over fewer years than immigrants from Christian countries. Multivariate estimates indicate that the effects of fertility rates and religious composition of countries of origin and individual religiousness are of similar magnitude for post-migration fertility rates. The highest fertility outcomes are found among highly religious immigrants from Muslim countries migrating to relatively high fertility countries in Europe at an early fertile age.
\end{abstract}

\section{Keywords}

immigrant fertility - women - religion - religiousness - Europe - comparative data

Over recent years, Europe has experienced low fertility rates, less than 1.6 children per adult in the European Union since 2011. Low fertility has been balanced by massive immigration, particularly from high-fertility Muslim countries. This situation has led to concerns about the future religious composition of Europe (Lewis 2007), prompting studies investigating the fertility of immigrants and minority religious groups (Andersson 2004; Hackett et al. 2019; Milewski 2007; Stonawski et al. 2016).

(C) MORTEN BLEKESAUNE, 2020 | DOI:10.1163/2589742X-12347109

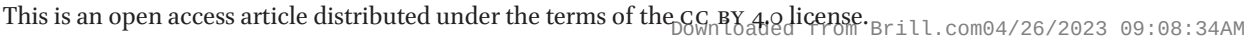


Consequences for future religious composition are not easily estimated because factors like immigration and fertility rates tend to change (Hackett et al. 2019; Peri-Rotem 2016). Further, religiousness also affects fertility (Frejka and Westoff 2008), and immigrants are more religious than native Europeans (van Tubergen and Sindradóttir 2011). Qualitative research indicates that religions can be particularly important following distress from immigration (Hirshmann 2004).

This article adds to the research on religious factors and immigrant fertility by investigating the roles of the religious composition of countries of origin and individual religiousness among female immigrants to Europe from Africa, Asia, and Latin America in rounds 5 to 8 of the European Social Survey (ESS). It adds to previous research on this topic by investigating multiple destination countries in contrast to previous research that has typically investigated single countries, or a few countries, with not always comparable data. It also compares the roles of religious factors with fertility rates in both countries of origin and country of residence.

Much research on immigrant fertility is limited to women. One reason is attributed to method, as the reporting of children is more reliable for women than for men. Furthermore, several studies show elevated levels of fertility during the first years after immigrating to Europe (Andersson 2004; Milewski 2007; Robards and Berrington 2016). This is partly due to immigrations driven by marriage (Kulu and Gonzalez-Ferrer 2014; Andersson 2004; Kulu 2005). Some studies also show that the high fertility rates after immigration is somewhat balanced by low fertility rates in the years preceding migration to Europe (Coleman and Dubuc 2010; Dubuc 2012). Hence, we can only estimate the fertility of immigrant women if using both pre- and post-migration rates (Hoem 2014; Sobotka 2008; Toulemon 2004).

Much research on immigrant fertility departs from socialization theory, which argues that the fertility of immigrants reflects the fertility preferences in their country of origin and that these effects are relatively stable over the life course (Kulu and Milewski 2007). However, the stability of fertility preferences can vary, depending on their sources.

Country of origin fertility preferences can be captured by various indicators, including actual fertility rates and religious composition. Religious composition is significant due to the moral orders that religions provide to guide human behaviour (McQuillan 2004; Smith 2003). Religions also offer guidelines to sexuality, gender roles, and the role of the family (McQuillan 2004; 
Norris and Inglehart 2004), and they provide psychological and social rewards to people with multiple children (Lehrer 2004). Such moral orders and associated guidelines are likely to remain important even after migrating to Europe.

High fertility among some members of a society may also affect the fertility of other members due to learned behavior within social groups-from associated norms and anticipated reactions - or because of the perceived benefits of participating in social networks that include children (Lois and Becker 2014). Such 'adaptive' characteristics of a country of origin are likely to lose importance after migrating to Europe.

Smith (2003) argues that the moral orders associated with the various religions affect not only believing but also secular and non-believing individuals in a society. Hence, the religious composition of countries of origin may affect the demographic behaviour of both religious and non-religious immigrants. Individual religiousness is correlated with fertility rates in most countries (Frejka and Westoff 2008). There is also the possibility that individual religiousness has stronger effects on people coming from countries dominated by pro-natalist religions (Heckert and Teachman 1985).

Socialization theory may be contrasted with adaptation theory arguing that an individual's current social context rather than the childhood environment is important for fertility behaviour (Kulu and Milewski 2007). This explanation has both cultural and economic dimensions. The cultural dimension is like the socialization hypothesis but instead argues that fertility preferences tend to change after immigration and approach the preferences and behaviour of the native population in the new country. It corresponds to the adaptive preferences mentioned above for the characteristics of countries of origin. The economic aspect means that the cost of raising children varies between countries of residence because of different levels of prosperity or different levels of public support to families with children, factors that likely affect fertility (DiPrete et al. 2003; Rindfuss et al. 2016).

The disruption hypothesis argues that long-distance migration may disrupt family formation processes because migration is associated with economic stress, limited social networks, or separate living of partners (Goldstein 1973; Milewski 2007). The hypothesis of inter-related life events argues, somewhat contrary, that migration may coincide with family formation processes such as the formation of marital partnerships or family reunion (Kulu et al. 2019; Milewski 2007).

There is also the possibility that migrants choose destination countries that facilitates their fertility preferences (Kulu et al. 2019). For example, highfertility countries could be seen as a more attractive environment for migrants planning to have children because they are associated with family-friendly 
environments, perhaps because of more ambitious family policies that may make it more affordable to raise children (Rindfuss et al. 2016). This research cannot distinguish between this selection hypothesis and the hypothesis that immigrants adapt to the economic costs of raising children in a new country.

The empirical analysis investigated rounds 5 to 8 of the Ess, collected from 2010 to 2017. The data provided information about how many years since an immigrant first came to live in the country, in contrast to previous rounds of the Ess that used rough brackets of the timing migration (for example, 11-20 years ago, more than 20 years ago). The Ess identified the number of children living in the household, their age, and their relationship to the respondent. It did not distinguish between biological children, stepchildren, adopted children, or foster children. Hence, we had to make assumptions regarding the 'fertility' decisions of female immigrants. First, we assumed that children are members of their mother's household until their 18th birthday. This assumption corresponded to the 'own-child' approach in demographic research (Dubuc 20o9; Coleman and Dubuc 2010). Second, we investigated the women's decision to have children rather than carrying children herself, thus assuming having a stepchild, an adopted child or a foster child is a decision to have children in line with a biological child. For simplicity, we still used the term fertility.

We constructed a data matrix for the probability of having children born over the previous 18 years. It can have up to 18 observations for each woman of fertile age (aged 15-44), from 1992 (for Ess round 5 collected in 2010) to 2016 (the previous year for Ess round 8 data collected in 2017). For each of these years, fertility rates in countries of birth (in Asia, Africa, and Latin America) and countries of residence (in Europe) were added, using data from the world development indicators at The World Bank (July 2019). The analysis included countries (of origin and residence) with at least five responding women of fertile age. It comprised 1,667 immigrant women who were born in 68 different countries in Asia, Africa, and Latin America and who were currently living in 22 different European countries. The outcome variable had the value 1 for each year a child living in the household was born and o if no child was born that year. Fertility before and after immigration was investigated in separate statistical models.

Explanatory variables also included age each year, age at immigration, the religious composition of countries of origin, and individual religiousness as 
indicated by a o-10 item in the Ess. Religious composition of countries of origin was collected from the World Religion Dataset of the Association of Religion Data Archives for 2010. It was investigated as the proportions of national populations being Christians or Muslims in 2010 because of the small number of other religions in the data. The results indicated that migrants from Christian and Muslim countries have different fertility rates. Hence, a first analysis merely compared female immigrants from these two groups of countries, as indicated by a figure of more than $5^{\circ}$ percent of one of these religions. This analysis included 18,050 yearly observations for 1,344 women (674 of Christian and 670 of Muslim countries of origin). The second analysis included all immigrants, with 22,712 yearly observations for 1,667 women. Two children born the same year $(n=33)$ were represented by two records, meaning that the full data matrix had 22,745 records $(22,712+33)$.

The data were investigated using logistic regression models that controlled for age and age squared (the cubic term was not significant). Test statistics were adjusted for the multiple observations for each respondent (immigrant woman) using the cluster option in Stata. Regression results were investigated using percentage point differences calculated as average marginal effects in order to facilitate comparisons between samples and models (Mood 2010) in combination with probabilities of having a child and the predicted number of children (total fertility) over reproductive age (15-44 years) in life tables estimated from logit coefficients.

Standard statistical tests assume independent observations, which was violated by the current data because they were grouped into two sets of clusters: individuals from the same country of origin are more similar than individuals from different countries, and migrants residing in the same countries are more similar than migrants residing in different countries because they are exposed to the same regional characteristics. This analysis corrected the standard errors for its two-way (non-hierarchical) clusters using a method presented by Cameron and colleagues (2011). It estimated the regression models with cluster robust standard errors (using the cluster option in Stata) with data first clustered on countries of origin $(n=68)$, then clustered on countries of residence $(\mathrm{n}=22)$, and next on the combination of countries of origin and region of residence $(n=437)$. Finally, we created a new variance matrix that subtracted the latter matrix (with 437) from the sum of the first two matrices (with 68 and 22 clusters respectively).

Table 1 shows descriptive statistics for the yearly observations, excluding the second year for women with two children born the same year. Fertile age was defined as $15^{-44}$ with a mean of 31 years. The average age was 29 for all observation years; 25 before migration to 31 after migration. On average, $6.6 \%$ of the 
TABLE 1 Descriptive statistics of the observation years for immigrant women. Mean values are also split before vs. after migration.

\begin{tabular}{lcccccc}
\hline \multicolumn{2}{c}{ Mean values } & & S.D. & Low & High \\
& All years & Before & After & All years & & \\
& & & & & & \\
\hline Child(ren) born & $6.7 \%$ & $4.2 \%$ & $7.8 \%$ & & 0 & 2 \\
Age (that year) & 29.3 & 24.2 & 31.4 & 7.8 & 15 & 44 \\
Christian c. origin & $42.3 \%$ & $44.8 \%$ & $41.2 \%$ & & 0 & 97 \\
Islamic c. origin & $36.8 \%$ & $32.4 \%$ & $38.6 \%$ & & 0 & 100 \\
Religiousness O-10 & 6.2 & 6.7 & 6.0 & 3.1 & 0 & 10 \\
Fertility c. origin & 3.2 & 3.3 & 3.2 & 1.56 & 1.1 & 7.7 \\
Age at migration & 21.2 & 28.6 & 18.1 & 10.7 & 0 & 43 \\
Fertility Europe & & & 1.6 & 0.24 & 1.1 & 2.2 \\
\#women & 1.667 & 880 & 1,667 & & & \\
\#years observed & 22,712 & 6,753 & 15,959 & & & \\
\hline
\end{tabular}

women obtained a child each year observed, somewhat higher (7.8\%) after than before migration (4.1\%).

The mean age when migrating to Europe was 21 years. Fertility rates in countries of origin in Asia, Africa, and Latin America (labelled 'c. origin' in the tables) were on average 3.2 children per woman, varying from 1.1 to 7.7 for all combinations of countries of birth and observation years. European fertility rates (only calculated after arriving in Europe) varied from 1.1 to 2.2 with a mean of 1.64. For illustration, the main results are estimated at fertility rates of 1.4 and 1.9 children, corresponding to 26 and 84 percentiles distribution. The mean fertility rate in countries of origin was 1.9 times larger than in the countries of residence in Europe, and the associated standard deviation statistics were as much as 6.5 times larger in countries of origin than in Europe.

\section{$3 \quad$ Christian and Muslim Countries of Origin}

A first analysis compared female migrants from predominantly Christian and Muslim countries. Almost all countries of origin had more than one religion; hence, this analysis compared countries of origin with more than 50 percent Christians (with a mean of 87 percent Christians) with countries of origin with more than 50 percent Muslims (with a mean of 85 percent Muslims). 
TABLE 2 Percentage point differences in the probability to have a child related to own age and the origin in predominantly Christian (674 women) and Muslim countries (670 women) before and after migration. Average marginal effects with standard with errors in parentheses.

Pre migration

$>50 \%$ Christian h.c.

$>5 \circ \%$ Muslim h.c.

\begin{tabular}{lllll} 
(Age-30)/10 & -1.40 & $(.88)$ & -0.34 & $(1.4)$ \\
Age squared & $-3.62^{* *}$ & $(1.4)$ & $-6.57^{* *}$ & $(2.3)$ \\
Post migration & & & & \\
(Age-30)/10 & -0.69 & $(.92)$ & $-2.62^{* *}$ & $(.90)$ \\
Age squared & $-5.17^{* * *}$ & $(.79)$ & $-9.87^{* * *}$ & $(.50)$ \\
Fertility Europe & $6.76^{* * *}$ & $(1.5)$ & $5.24^{* * *}$ & $(1.5)$ \\
Migration age/10 & $0.53 \dagger$ & $(.30)$ & $1.42^{* *}$ & $(.47)$ \\
$1-2$ years after $(1,0)$ & $1.77^{*}$ & $(1.1)$ & 2.20 & $(1.5)$ \\
\hline
\end{tabular}

$* * * 0.001,{ }^{* *}<0.01,{ }^{*}<0.05, \dagger<0.1$

Table 2 presents the regression results calculated as average marginal effects. While most marginal effects vary between the two groups of female migrants, only the age effect varied significantly between migrants from Christian and Muslim countries. These results are also presented graphically in Figure A. Female immigrants from Muslim countries have higher fertility, and they compress their fertility into fewer years than immigrants from Christian countries.

The graph shows that females migrating during fertile age (at 30 years) had much higher fertility rates after than before migrating to Europe, and they have particularly high fertility rates during the first two years after immigration. This pattern is the same irrespective of whether they come from a Christian or a Muslim country.

Figure B presents (life table) estimates for fertility outcomes (number of children) for the two groups of female immigrants over their reproductive age (15-44 years). It combines information on the characteristics of immigrants (age at immigration), countries of origin (religious composition), and country of residence (fertility rate, labelled 'Fertility Europe' in the tables). The mean difference between immigrants from Muslim countries and Christian countries when using all six groups ( 3 age groups and 2 levels of European fertility) in the graph is 0.38 more children when migrating from a Muslim rather than a Christian country. When considering ages at immigration, the highest fertility is for those immigrating at young fertile age-here, 20 years. The 


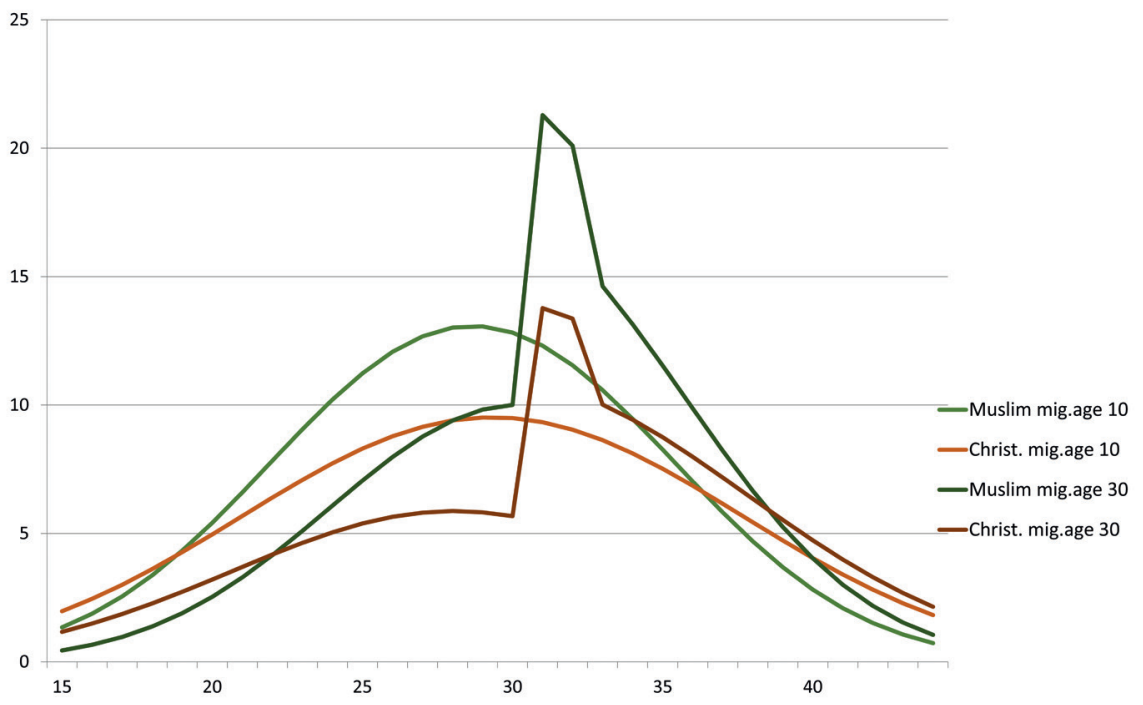

FIGURE A Age distributions of the percentage probability of having a child during fertile age (15-44 years), calculated from coefficients corresponding to the models in Table 2

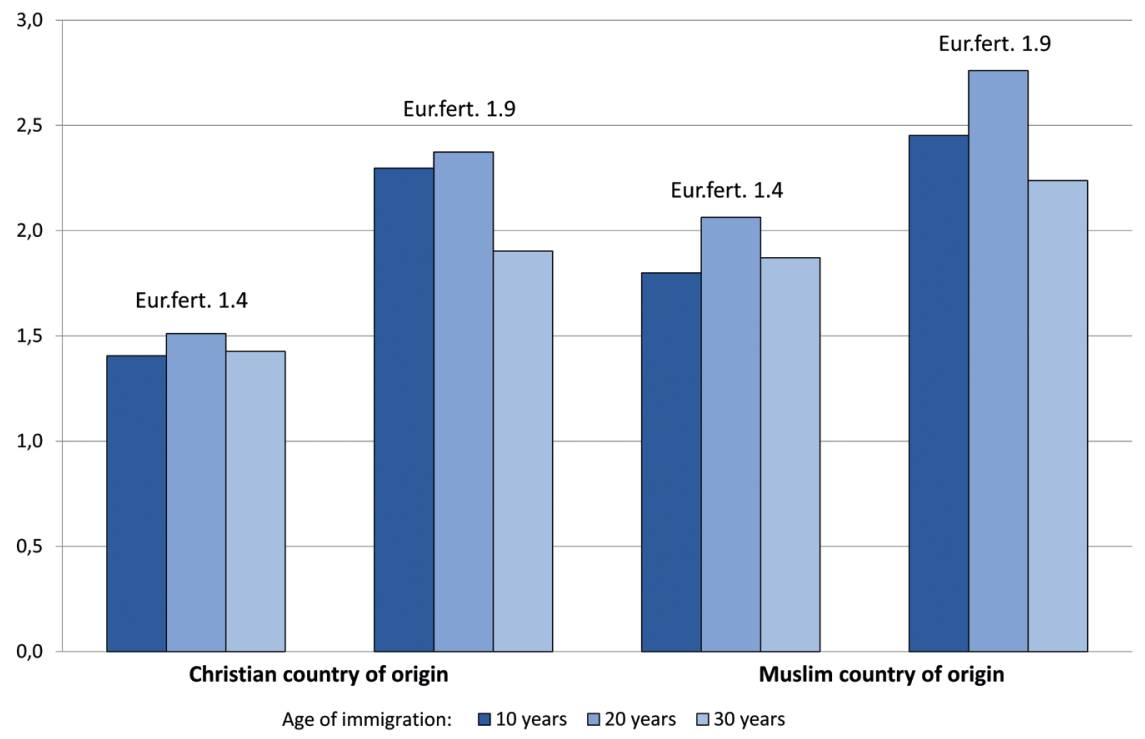

FIGURE B Predicted fertility, by the combinations of country of origin (Christian or Muslim), European fertility rates (1.4 or 1.9 children) and age at migrating to Europe (10, 20 or 30 years) 
TABLE 3 Post-migration percentage point differences in the probability to have a child — related to age and being born in Christian and Muslim countries, adding individual religiousness to the results in Table 2. Average marginal effects with standard with errors in parentheses.

Post migration

\begin{tabular}{ll} 
(Age-30)/10 & -0.62 \\
Age squared & $-5.15^{* * *}$ \\
Fertility Europe & $6.48^{* * *}$ \\
Migration age $/ 10$ & 0.33 \\
1-2 years after $(1,0)$ & $1.82 \dagger$ \\
Religiousness $(0-1)$ & $2.19^{*}$ \\
\hline
\end{tabular}

$(.91)$
$(.81)$
$(1.4)$
$(.28)$
$(1.0)$
$(1.0)$

$>50 \%$ Muslim h.c.

$-2.45^{* *}$
$-9.79^{* * *}$
$4.08^{* *}$
$1.23^{*}$
2.18
$4.47^{*}$

${ }^{* * *}<0.001,{ }^{* *}<0.01,{ }^{*}<0.05, \dagger<0.1$

largest difference between immigrants from Muslim and Christian countries is among those migrating to a low-fertility country in Europe at age 20 (0.55 more children), and the smallest difference is for those migrating to a high-fertility country at age 10 (o.16 more children).

These estimates also allow us to compare the number of children of migrants with national levels where they reside, using the 1.4 and 1.9 levels. This comparison indicates that immigrants from Muslim countries have 0.55 more children, and immigrants from Christian countries have 0.17 more children than the national levels. The details indicate that female immigrants from Christian countries have a similar number of children as national levels if migrating to a low-fertility country in Europe (about 1.4 children). This is also true for female migrants from predominantly Christian countries migrating at age 30 to a high-fertility European country (about 1.9 children). However, if migrating at a younger age to a high-fertility country, female immigrants have more children than native Europeans, here estimated as 0.47 more children (2.37-1.90) if migrating from a Christian country at age 20 , and as much as 0.86 more children (2.76-1.90) if migrating from a Muslim country at age 20, the largest level and difference compared to national levels in the graph.

A striking finding is a strong correlation between the fertility of immigrants and fertility rates in countries of residence in Europe. This effect is seemingly higher for immigrants than for natives. If increasing European fertility rates with 0.5 (from 1.4 to 1.9) children, the fertility of immigrants increases with o.88 children if coming from a predominantly Christian country at a young age 
(mean of 10 and 20 years) and 0.67 children if migrating from a predominantly Muslim country.

Table 3 merely adds individual religiousness (here divided by 10, indicating a o to 1 range) to the post-migration estimates in the lower part of Table 2. It shows a strong relationship between individual religiousness and fertility among female migrants from predominantly Muslim countries, while this effect could weaken among female migrants from predominantly Christian countries. The difference between the two estimates is not significant, however.

\section{Immigrants from All the Countries}

Table 4 investigates pre-migration fertility related to countries of origin fertility rates and religious composition among all female immigrants from Asia, Africa, and Latin America. Christian and Muslim countries of origin are investigated at proportions being either Christians or Muslims in countries of origin. Pre-migration fertility rates are strongly related to the general fertility rates in countries of origin. Religious composition does not seem to affect premigration fertility beyond a more general effect of the fertility rates of countries of origin.

Table 5 investigates post-migration fertility rates and includes more characteristics. Immigrants from Muslim countries also have higher fertility rates after migrating to Europe than immigrants from Christian countries $(\mathrm{z}=2.47)$, and in this case, the higher fertility does not explain the difference in their countries of origin $(\mathrm{z}=2.37)$. The further results show that the fertility rates in

TABLE 4 Percentage point differences in the probability to have a child—related to own age, religious composition and fertility in country of origin. Average marginal effects with standard with errors in parentheses.

\section{Pre-migration}

\begin{tabular}{lll} 
(Age-30)/10 & -0.40 & $(.57)$ \\
Age squared & $-4.57^{* * *}$ & $(1.2)$ \\
Christian c. origin & -0.19 & $(.99)$ \\
Muslim c. origin & 0.18 & $(1.1)$ \\
Fertility c. origin & $0.97^{* * *}$ & $(.15)$ \\
\hline$* * *<0.001,{ }^{* *}<0.01,{ }^{*}<0.05, \dagger<0.1$ & &
\end{tabular}


Europe have smaller effects on fertility of immigrants in this analysis (Table 5) than in Table 2, indicating that these effects could be stronger for immigrants from both Christian and Muslim countries than for other countries of origin.

This analysis (Table 5) also allows for comparing the role of fertility rates in countries of origin versus countries of residence after migrating to Europe. A unit (one child) increase in the fertility rate in Europe has an 11 times stronger effect in the fertility of immigrant women compared to (current) fertility rates in their country of origin. We should keep in mind, however, that there is a lot more variation in the fertility rates between countries in the South than between European countries. We may thus conclude that both fertility rates affect the demographic behaviour of immigrant women.

We may also compare the relative importance of the various characteristics, internally_-for instance, religious compositions versus fertility rates in countries of origin. This comparison indicates that the religious composition is almost as important as the fertility rates in countries of origin because the adjusted difference between Muslims and Christians countries (for typical proportions, net of fertility rates) corresponds to 1.6 standard deviations statistics of the fertility rates of countries of origin $\left(\left(1.44^{*} 0.86+0.99^{*} 0.85\right) /\left(0.4^{*} 3.2\right)\right)$. A similar comparison indicates that the religious composition of countries of origin is as important as individual religiousness because the net difference between Muslims and Christians countries corresponds to 2.8 standard deviations statistics in religiousness $\left(\left(1.08^{*} .85^{+0.99 *} .85\right) /\left(2.00^{*} 0.31\right)\right)$.

TABLE 5 Percentage point differences in the probability to have a child related to own age, religious composition and fertility in countries of origin. Average marginal affects with standard with errors in parentheses.

Post-migration

$$
\text { (Age-30)/10 }
$$

Age squared

Christian c. origin

Muslim c. origin

Religiousness (o-1)

Fertility c. origin

Fertility Europe

Migration age/10

$1-2$ years after $(1,0)$
2

$\begin{array}{lll}-1.27^{* *} & (.44) & -1.22^{* *} \\ -7.85^{* * *} & (.69) & -7.81^{* * *} \\ -0.86 & (1.2) & -0.99 \\ 1.44 & (1.1) & 1.08 \\ & & 2.00^{*} \\ 0.40^{*} & (.17) & 0.34^{*} \\ 4.32^{* * *} & (1.1) & 4.01^{* * *} \\ 1.08^{* * *} & (.27) & 0.93^{* *} \\ 1.90^{*} & (.82) & 1.92^{*}\end{array}$

***< $<0.001,{ }^{* *}<0.01,{ }^{*}<0.05, \dagger<0.1$ 
This research reveals a strong relationship between the fertility of female immigrants and two characteristics of countries of origin: fertility rates and religious composition. The religious composition is not related to pre-migration fertility when also controlling for fertility rates. The religious compositions of countries of origin become important for the fertility of immigrant women beyond the role of its fertility rates after migrating to Europe as well as beyond the role of individual religiousness. This finding is consistent with the argument that religions provide moral orders that guide human behaviour (Smith 2003), and that these preferences remain strong even after long-distance migration (McQuillan 2004). There is also the possibility that trauma following longdistance migration may strengthen emotional attachment to such moral orders (Hirshmann 2004).

There is little previous research on how the characteristics of countries of residence affect the fertility of immigrant women. The study finds an astonishingly strong relationship between immigrant fertility and the fertility rates in countries of residence in Europe. By increasing fertility in Europe by 0.5 children, the fertility outcomes of immigrants increases with as much as o.67-0.88 children. One explanation could be a preference many immigrants have for raising children, along with limited financial resources that could make their fertility sensitive to factors such as the prosperity or the financial support the country of residence offers to families with children. The northwestern region of Europe has the highest fertility rates, the highest income levels, and the most ambitious family policies in Europe (Thévenon 2011). There is also the possibility that immigrants planning to have children chose to migrate to these countries because of these factors, as indicated by the selection hypothesis.

Fertility peaks over the first few years after migrating to Europe. This finding is consistent with previous research (Andersson 2004; Milewski 2007; Robards and Berrington 2016). We also tested for expected lower fertility over the first few years before migrating to Europe, as reported in some previous studies (Coleman and Dubuc 2010; Dubuc 2012). We found no such tendencies in the ESS. Thus, the disruption hypothesis (i.e., migration leads to low fertility over the years before and after migration) is not supported by these data. Our findings are consistent with the hypothesis about inter-related life events, however. Most likely, some female migration is associated with family formation processes (Kulu and Gonzalez-Ferrer 2014; Andersson 2004; Kulu 2005). A more direct test would require partnership history data, however. 
Much research on immigrant fertility and the fertility of different religious groups aims to estimate future ethnic or religious composition in host countries. The estimates provided in the current analysis using Ess data show smaller differences between immigrants and natives than some of the results presented in previous research (e.g., Hackett et al. 2019). Immigrants from Muslim countries have an estimated 0.55 more children than natives in the current study if using the mean of the mean difference of all six comparisons in Figure B. One explanation could be that the gap between Muslim and Christian fertility has narrowed over recent decades (see Westoff and Frejka 2007). There is also the possibility that highly-fertile immigrants are underrepresented in survey data like the Ess.

This analysis shows substantial variation between groups of female immigrants related to age, the timing of migration, and age at immigration. One implication is that comparing fertility between immigrant groups and natives can give distorted results if not considering the entire reproductive period. Estimates of fertility outcomes from limited observation periods should include pre-migration fertility, the timing of fertility as related to the event of migration, as well as the possibility that immigrants from Muslim countries get children over a relatively compressed period compared to immigrants from predominantly Christian countries.

The current study allows for investigating how the characteristics of both countries of origin and country of residence in Europe affect the fertility of immigrant women. Compared to some data sources, it also allows for investigating pre-migration fertility and years of immigration. Further, because the immigrants come from many countries, and they reside in multiple countries, no single group is sufficiently numerous to drive any of the results presented. Survey data such as the Ess have limitations regarding sample size and participation rates, however. We do not know much about how far participation rates vary for different groups of migrants or how far this could affect estimated fertility rates, certainly not when comparing data from several countries. The number of immigrants is also not well known in several European countries. Another limitation is an inaccurate measure of fertility as it relies on the presence of children in the household. British data (Dubuc 2012) indicate a slight underestimation of immigrant fertility because of children left behind, typically over the first few years after immigration. Most likely, children left behind 
leads to an underestimation of the fertility of women migration at age 30 in the current study. It may underestimate the fertility of migrant workers because this group of immigrants is known to have children left behind in previous studies (e.g., Peng and Wong 2016).

\section{Conclusions and Policy Implications}

A surprisingly strong correlation between the country of residence fertility and the fertility outcomes of immigrants indicates that immigrant fertility is subject to the same factors as those affecting infants. Still, some immigrants have higher fertility than natives, particularly highly religious immigrants from Muslim countries. When also considering previous research (Westoff and Frejka 2007) and the (first) demographic transition, there are reasons to believe that the difference is becoming smaller. However, there is the possibility that individual religiousness might counteract such tendencies.

\section{References}

Andersson, G. 2004. "Childbearing after Migration: Fertility Patterns of Foreign-born Women in Sweden." International Migration Review 38 (2): 747-775.

Cameron, A.C., J.B. Gelbach, and L.M. Douglas 2011. "Robust Inference with Multiway Clustering." Journal of Business and Economic Statistics 29 (2): 238-249.

Coleman, D.A., and S. Dubuc, S. 2010. "The Fertility of Ethnic Minorities in the U K, 1960s-20o6." Population Studies 64 (1): 19-41.

DiPrete, T.A., S.P. Morgan, H. Engelhardt, and H. Pacalova. 2003. "Do Cross-National Differences in the Costs of Children Generate Cross-National Differences in Fertility Rates?" Population Research and Policy Review 22 (5-6): 439-477

Dubuc, S. 2009. "Application of the Own-Children Method for Estimating Fertility by Ethnic and Religious Groups in the U K." Journal of population research 26 (3): 207-225.

Dubuc, S. 2012. "Immigration to the U K from High-Fertility Countries:Intergenerational Adaptation and Fertility Convergence." Population and Development Review 38 (2): $353-368$.

Frejka, T., and C.F. Westoff. 2008. "Religion, Religiousness and Fertility in the US and in Europe." European Journal of Population 24 (1): 5-31.

Goldstein, S. 1973. "Interrelations between Migration and Fertility in Thailand." Demography 10 (2): 225-241. 
Hackett, C., M. Stonawski, M. Potančoková, P. Connor, A.F. Shi and J. Marshall. 2019. "Projections of Europe's Growing Muslim: Population Under Three Migration Scenarios." Journal of Religion and Demography 6: 87-122.

Heckert, A., and J.D. Teachman. 1985. "Religious Factors in the Timing of Second Births." Journal of Marriage and Family 47 (2): 361-367.

Hirshman, C. 2004. "The Role of Religion in the Origins and Adaptation of Immigrant Groups in the United States." International Migration Review 38 (3): 1206-1233.

Hoem, J.M. 2014. "The Dangers of Conditioning on the Time of Occurrence of One Demographic Process in the Analysis of Another." Population Studies 68 (2):151-159. Kulu, H. 2005. "Migration and Fertility: Competing Hypotheses Re-Examined." European Journal of Population 21 (1): 51-87.

Kulu, H., and A. Gonzalez-Ferrer. 2014. "Family Dynamics among Immigrants and Their Descendants in Europe: Current Research and Opportunities." European Journal of Population 30 (4): 411-435.

Kulu, H., and N. Milewski. 2007. "Family Change and Migration in the Life Course: An Introduction." Demographic Research 27 (19): 567-59o.

Kulu. H., N. Milewski, T. Hannemann, and J. Mikolai. 2019. "A Decade of Life-Course Research on Fertility of Immigrants and Their Descendants in Europe." Demographic Research 40 (46): 1345-1374.

Lehrer, E.L. 2004. "Religion as a Determinant of Economic and Demographic Behavior in the United States." Population and Development Review 30 (4): 707-726.

Lewis, B. 2007. "Muslims About to Take over Europe." International Jerusalem Post, 29 January.

Lois, D., and O.A. Becker. 2014. "Is Fertility Contagious? Using Panel Data to Disentangle Mechanisms of Social Network Influences on Fertility Decisions." Advances in Life Course Research 21: 123-134.

McQuillan, K. 2004. "When Does Religion Influence Fertility?" Population and Development Review 30 (1): 25-56.

Milewski, N. 2007. "First Child of Immigrant Workers and Their Descendants in West Germany: Interrelation of Events, Disruption, or Adaptation?" Demographic Research 17 (29): 859-896.

Mood, C. 2010. "Logistic Regression: Why We Cannot Do What We Think We Can Do, and What We Can Do About It." European Sociological Review 26 (1): 67-82.

Norris, P., and R. Inglehart. 2004. Sacred and Secular: Religion and Politics Worldwide. New York: Cambridge University Press.

Peng, Y.N., and O.M.H. Wong 2016. "Who Takes Care of my Left-Behind Children? Migrant Mothers and Caregivers in Transnational Child Care." Journal of Family Issues 37 (14): 2021-2044

Peri-Rotem, N. 2016. "Religion and Fertility in Western Europe: Trends across Cohorts in Britain, France and the Netherlands." European Journal of Population 32 (2): 231-265. 
Rindfuss, R.R., M.K. Choe, and S.R. Brauner-Otto 2016. "The Emergence of Two Distinct Fertility Regimes in Economically Advanced Countries." Population Research and Policy Review 35 (3): 287-304.

Robards, J. and A. Berringston. 2016. "The Fertility of Recent Migrants to England and Wales." Demographic Research 34 (article 36): 1037-1052.

Smith, C. 2003. Moral, Believing Animals: Human Personhood and Culture. Oxford, U K: Oxford University Press.

Sobotka, T. 2008. "The Rising Importance of Migrants for Childbearing in Europe.” Demographic Research 19 (article 9): (225-247).

Stonawski, M., M. Potančoková, and V. Skirbekk. 2016. "Fertility Patterns of Native and Migrant Muslims in Europe." Population, Space and Place 22 (6): 552-567.

Thévenon, O. 2011. "Family Policies in the OECD Countries: A Comparative Analysis." Population and Development Review 37 (1): 57-87.

Toulemon, L. 2004. "Fertility among Immigrant Women: New Data, a New Approach." Population \& Societies, 400: 1-4.

van Tubergen, F., and J.I. Sindradóttir. 2011. "The Religiosity of Immigrants in Europe: A Cross-National Study." Journal for the Scientific Study of Religion 50 (2): 272-288. Westoff, C.F., and T. Frejka. 2007. "Religiousness and Fertility among European Muslims." Population and Development Review 33 (4): 785-809. 